\title{
Intravenous fibrinolysis plus endovascular thrombectomy versus direct endovascular thrombectomy for anterior circulation acute ischemic stroke: clinical and infarct volume results
}

\author{
Massimo Gamba ${ }^{1 *}$, Nicola Gilberti ${ }^{1}$, Enrico Premi ${ }^{1}$, Angelo Costa ${ }^{1}$, Michele Frigerio ${ }^{2}$, Dikran Mardighian², \\ Veronica Vergani ${ }^{1}$, Raffaella Spezi ${ }^{1}$, Ilenia Delrio ${ }^{1}$, Andrea Morotti ${ }^{4}$, Loris Poli ${ }^{3}$, Valeria De Giuli ${ }^{3}$, Filomena Caria ${ }^{3}$, \\ Alessandro Pezzini ${ }^{3}$, Roberto Gasparotti ${ }^{2}$, Alessandro Padovani ${ }^{3}$ and Mauro Magoni ${ }^{1}$
}

\begin{abstract}
Background: endovascular therapy (ET) is the standard of care for anterior circulation acute ischemic stroke (AIS) caused by large vessel occlusion (LVO). The role of adjunctive intravenous thrombolysis (IVT) in these patients remains unclear. The present study aims to investigate whether IVT followed by ET (CoT, combined therapy) provides additional benefits over direct ET for anterior circulation AIS with LVO.
\end{abstract}

Methods: we achieved a single center retrospective study of patients with AIS caused by anterior circulation LVO, referred to our center between January 2014 and January 2017 and treated with ET. Functional recovery (modified Rankin at 3-months follow-up), recanalization rate (thrombolysis in cerebral infarction $[\mathrm{TICl}$ score) and time, early follow-up brain CT scan infarct volume (EFIV) (for recanalized patients only), symptomatic intracerebral hemorrhage $(\mathrm{s} \mid \mathrm{CH})$ and 3-month mortality were the outcomes of interests. Independent predictors of the outcomes were explored with multivariable logistic regression.

Results: 145 subjects were included in the study, of whom 70 underwent direct ET and 75 were treated with CoT. Functional independence at 3-months was more frequent in CoT subjects compared to patients who received direct ET (mRS score 0-1: 48.5\% vs 18.6\%; $P<0.001$. mRS score 0-2: 67.1\% vs 37.3\%; $P<0.001$ ); CoT patients had also higher first-pass success rate $(62.7 \%$ vs $38.6 \%, P<0.05)$, higher recanalization rate $(84.3 \%$ vs $65.3 \% ; P=0.009)$ and, in recanalized subjects, smaller EFIV $(16.4 \mathrm{ml}$ vs $62.3 \mathrm{ml} ; P=0.003)$. Mortality and intracranial bleeding did not differ between the two groups. In multivariable regression analysis, low baseline NIHSS score $(P<0.05)$, vessel recanalization $(P=0.05)$ and CoT $(P=0.03)$ were independent predictors of favorable outcome at three months.

Conclusions: CoT appears more effective than ET alone for anterior circulation AIS with LVO, with similar safety profile. Keywords: Ischemic stroke, Intravenous thrombolysis, Endovascular therapy, Combined therapy, Large vessels occlusion

\footnotetext{
* Correspondence: massimo.gamba@asst-spedalicivili.it

${ }^{1}$ Stroke Unit, Neurologia Vascolare, ASST Spedali Civili di Brescia, Piazzale

Spedali Civili 1, Brescia 25123 Brescia, Italy

Full list of author information is available at the end of the article
}

(c) The Author(s). 2019 Open Access This article is distributed under the terms of the Creative Commons Attribution 4.0 International License (http://creativecommons.org/licenses/by/4.0/), which permits unrestricted use, distribution, and reproduction in any medium, provided you give appropriate credit to the original author(s) and the source, provide a link to the Creative Commons license, and indicate if changes were made. The Creative Commons Public Domain Dedication waiver (http://creativecommons.org/publicdomain/zero/1.0/) applies to the data made available in this article, unless otherwise stated. 


\section{Background}

Endovascular therapy (ET) represents the standard of care for anterior circulation acute ischemic stroke (AIS) due to large vessel occlusion (LVO) [1-3]. It remains unclear whether intravenous thrombolyisis preceding ET provides additional benefit compared to direct ET. The administration of IVT may have important drawbacks such as potential risk of bleeding, especially in patients taking single or dual antiplatelet therapy, delay in beginning of ET and clot fragmentation leading to distal arterial embolism [4]. Conversely, the use of tissue plasminogen activator (tPA) may produce recanalization by itself or may aid thrombectomy by softening the thrombus and enhance overall reperfusion by accelerating lysis of distal thrombi, preserving microvascular perfusion downstream to the arterial occlusion [4]. Recent observational studies and 2 meta-analyses showed conflicting results [5-9]. A large registry, including 599 direct ET and 567 CoT therapy patients found no difference between the 2 groups in terms of safety and efficacy [10]. Another registry of 276 (138 in each group) tPA-eligible patients within a 4.5 -h time window, again found no significant difference between CoT and ET for both safety and efficacy parameters [11]. Since the currently available evidence on this topic is inconclusive, 4 randomized clinical trials are ongoing (SWIFT DIRECT, NCT03469206; MR CLEAN NOIV, http://www.mrcleannoiv.nl, DIRECT MT, NCT03469206; DIRECT SAFE NCT03494920) but no one has been published to date.

The goal of our study was to compare CoT versus ET in a real world single center cohort of AIS patients with LVO, exploring the safety profile of these two treatments and comparing their effect on radiological and functional outcomes [12-14].

\section{Methods}

Subjects. single-center retrospective observational study. All AIS patients referring to our center (Stroke Unit, Neurologia Vascolare, ASST "Spedali Civili", Brescia, Italy) between January 2014 and January 2017 were screened for the study. Subjects with anterior circulation AIS due to LVO and fulfilling AHA/ASA criteria for ET [3] were included in the analysis. LVO was diagnosed by computed tomography angiography as an occlusion involving intracranial terminal internal carotid artery (tICA) and/or M1-proximal M2 tracts of middle cerebral artery (MCA). Patients fulfilling criteria for IVT and ET were allocated to CoT group while subjects with IVT exclusion criteria were included in ET group [3].

Patients treated with CoT received intravenous full-dose rtPA $(0.9 \mathrm{mg} / \mathrm{kg})$ followed by ET, with groin puncture performed at the same time of rtPA bolus or as soon as possible during IVT infusion. Patients with undetermined time of symptoms onset and those with ET performed after complete tPA administration were excluded. Written informed consent was obtained by patients or relatives. All the procedures of the study conformed to the Helsinki Declaration.

Demographics, vascular risk factors, laboratory exams, imaging findings and vital signs were collected. Stroke etiology, according to Trial of ORG 10172 in acute stroke treatment (TOAST) criteria 15, was assessed. All patients underwent a baseline brain computed tomography (CT) with Alberta Stroke Program Early Computed Tomography Score (ASPECTS) evaluation [15] and a follow up brain CT at 2-4 days from onset. Baseline National Institute of Health Stroke Scale (NIHSS) were recorded. The number of passes during ET have been recorded as well and the recanalization degree has been assessed on digital subtraction angiography (DSA) according to TICI criteria; Good recanalization was defined as TICI grade $2 b$ or 3 [16].

The main safety outcomes of interest were: symptomatic intracranial hemorrhage $(\mathrm{sICH})$ defined as deterioration in NIHSS $\geq 4$ associated with evidence of any intracerebral hemorrhage on follow-up non-contrast cerebral CT, according to European Cooperative Acute Stroke Study II (ECASS II) [17] and mortality at 3 months follow up.

\section{Cerebral infarct volume measurement}

The Cerebral Infarct Volume (CIV) of all recanalized patients were manually delineated by one experienced neurologist (N.G.) on early follow-up brain CT scan (at 2-4 days after stroke). The infarct volume was delineated section-by-section by using ITK-SNAP 2.2.0 (http:// www.itksnap.org/pmwiki/pmwiki.php). Brain CT scan with $5 \mathrm{~mm}$ thick slices were used, considering acute cerebral infarct as new parenchymal hypodensities with respect to basal brain $\mathrm{CT}$. Infarct volume was measured manually contouring the parenchymal hypodensity of interest slice by slice. Software then calculated the volume of the selected area [12, 13]. Observer was blinded to all clinical information and outcome.

\section{Interventional procedures}

All procedures were performed under conscious sedation on a biplane angiography (Axiom Artis, Siemens, Erlangen, Germany) avoiding general anesthesia, if possible. Endovascular procedures consisted in thrombectomy with stent retrievers (Solitaire stent-Ev3 Inc. and Trevo stent-Stryker) or thromboaspiration (Penumbra 5 Max, Penumbra, Alameda, California, USA).

\section{Statistical analysis}

Univariate comparisons between the groups were made using Pearson's chi-squared test for categorical variables, the Mann-Whitney U test or Wilcoxon rank sum test for continuous variables. We assessed both clinical (mRS at 
90 days) and neuroradiological outcome (early follow-up Infarct Volume - EFIV - at 2-4 days CT scan, in well recanalized cases). Independent predictors of the outcomes of interest were explored with a multivariable forward stepwise binary logistic regression model. Variables known to be predictive of clinical outcome from the literature were entered into the initial model. SPSS package (v. 17.0, Chicago, IL, USA) was used for the analyses and $p$ values $<0,05$ were considered statistically significant.

\section{Results}

A total of 2248 AIS patients referred to our Hospital were screened and 145 subjects met the inclusion criteria of our study (70 in CoT and 75 in direct ET group). There was no significant difference between groups regarding age, gender, blood pressure, blood glucose, coronary disease, hypercholesterolemia and antithrombotic medications before stroke. 2 subjects were excluded because they were transferred to our Centre by HUB\&SPOKE mechanism late after ( $>60 \mathrm{~min}: 70$ and $75 \mathrm{~min}$ respectively) the conclusion of tPA administration: thrombectomy in these cases of AIS with LVO has been considered a rescue therapy after IVT failure's assessment. These patients presented both a bad clinical outcome (patient 1 died at 15 days for respiratory failure due to pneumonia; patient 2 had a 3-months $\mathrm{mRS}=3$ ). Stroke subgroups according to TOAST criteria, baseline NIHSS, ASPECTS scores and occluded vessel were also similar between the two groups (Table 1). Table 2 summarizes the causes of exclusion from IVT. Time-to-groin puncture and time-torecanalization were similar in the 2 groups. Recanalization rate was significantly higher in CoT group $(84.3 \%$ vs $65.3 \% ; P=0.009)$, as well as first-pass success rate $(62.7 \%$ vs $38.6 \%, P<0.05)$. CoT group presented a significantly higher functional independence rate at 3 -months followup (mRS score $0-1: 48.5 \%$ vs $18.6 \% ; P<0.001$. mRS score $0-2: 67.1 \%$ vs $37.3 \% ; P<0.001)$.

In recanalized subjects, EFIV was significantly smaller in the CoT group ( $16.4 \mathrm{ml}$ vs $62.3 \mathrm{ml} ; P=0.003)$. Safety outcome measures were similar between the two groups (Table 3).

In multivariable analysis, CoT was independently associated with higher odds of favorable functional outcome (OR, 3.75; 95\% CI, 1.09-12.85; $P=0.03$ ). Other predictors

Table 1 Baseline characteristics of the patients

\begin{tabular}{|c|c|c|c|}
\hline Characteristics & $\operatorname{CoT}(n=70)$ & Direct ET $(n=75)$ & $b$ \\
\hline Age, Mean (SD), y & $71.9(10.6)$ & $69.1(13.2)$ & $0.15^{2}$ \\
\hline Gender, n F (\%) & $32(45.7)$ & $38(50.6)$ & $0.49^{a}$ \\
\hline Baseline NIHSS, median (IQR) & $18(15-21)$ & $19(15-20)$ & $0.55^{c}$ \\
\hline \multicolumn{4}{|l|}{ Risk factors } \\
\hline Hypertension, n (\%) & $52(74.3)$ & $53(70.6)$ & $0.62^{a}$ \\
\hline Diabetes mellitus, n (\%) & $12(17.1)$ & $11(14.6)$ & $0.68^{a}$ \\
\hline Atrial fibrillation, $\mathrm{n}(\%)$ & $30(42.8)$ & $37(49.3)$ & $0.43^{a}$ \\
\hline Hyperlipidemia, n (\%) & $29(41.4)$ & $23(30.6)$ & $0.17^{a}$ \\
\hline Antiplatelet or anticoagulant use, n (\%) & $34(48.6)$ & $37(49.3)$ & $0.85^{a}$ \\
\hline Sistolic Blood Pressure, Mean (SD), mmHg & $145.6(12.6)$ & $147.3(24.8)$ & $0.70^{\mathrm{b}}$ \\
\hline Diastolic Blood Pressure, Mean (SD), mmHg & $81.9(15.3)$ & $81.1(12.5)$ & $0.77^{\mathrm{b}}$ \\
\hline Serum glucose, Mean (SD), mg/dl & $130.4(54.6)$ & $139.4(82.7)$ & $0.59^{b}$ \\
\hline ASPECTS score; median (IQR) & $9(8-10)$ & $9(8-10)$ & $0.06^{c}$ \\
\hline Cause of stroke (TOAST) & & & 0.7 \\
\hline Large-artery disease, (\%) & 23.4 & 20.0 & \\
\hline Small-artery disease, (\%) & 0.0 & 0.0 & \\
\hline Cardioembolic, (\%) & 54.7 & 55.0 & \\
\hline Other, (\%) & 4.7 & 6.6 & \\
\hline Unknown, (\%) & 17.2 & 18.4 & \\
\hline \multicolumn{4}{|l|}{ Site of occlusion } \\
\hline tICA, n (\%) & $9(12.8)$ & $22(29.3)$ & $0.06^{\mathrm{a}}$ \\
\hline MCA-M1 segment, n (\%) & $46(65.7)$ & $40(53.3)$ & \\
\hline MCA-M2 segment, n (\%) & $15(21.4)$ & $13(17.3)$ & \\
\hline
\end{tabular}

apearson's chi-squared test; ${ }^{b}$ Mann-Whitney test for unpaired groups; ${ }^{\circ}$ Wilcoxon rank sum test; IQR inter-quartile range, NIHSS National Institute of Health Stroke Scalem, SD standard deviation, MCA middle cerebral artery, tICA terminal ICA, PCSE potential cardiac sources of embolism, CoT combined therapy, ET endovascular therapy 
Table 2 Causes of IVT exclusion in patients with AIS

\begin{tabular}{ll}
\hline Causes of IVT exclusion, (\%) & \\
\hline Anticoagulant therapy & 28.6 \\
Brain or systemic lesions at risk of bleeding & 14.3 \\
Possible placement of vascular stent & 11.4 \\
Onset > 4.5 h & 14.3 \\
Major trauma & 7.1 \\
Recent surgery & 4.3 \\
Other reasons & 20.0 \\
\hline
\end{tabular}

IVT intravenous thrombolysis

of good outcome were lower baseline NIHSS (OR, 0.73; 95\% CI,0.62-0.86; $\mathrm{P}<0.05)$, and vessel recanalization $(\mathrm{OR}$, 7.30; 95\% CI, 0.60-88.62; $P=0.05$ ) (Table 4).

\section{Discussion}

Randomized clinical trials (RCTs) have definitively proven the effectiveness of endovascular approach for anterior circulation AIS with LVO [3]. In this context, the role of adjunctive IVT before ET remains unclear, presenting theoretically pros and cons highlighted in the background section. The main of our study is the independent association between CoT and favorable outcome, compared with direct ET. A higher rate of vessel recanalization and lower infarct volume at follow-up CT seem the plausible biological mechanisms mediating the beneficial effect of CoT on outcome.

Our findings therefore support the use administration of IVT before ET in eligible patients, in line with the recommendations of the American Heart Association / American Stroke Association guidelines [3]. The two excluded patients mentioned in the previous section, received thrombectomy too late after IVT conclusion: this therapeutic scheme different from CoT received by the other included subjects and, because of the short half-life
Table 4 Multivariate analysis

\begin{tabular}{lll}
\hline Variables & $P$ value & OR $(95 \% \mathrm{Cl})$ \\
\hline Baseline NIHSS & $<0.05$ & $0.73(0.62-0.86)$ \\
ASPECTS score & 0.07 & $0.59(0.33-1.05)$ \\
TICI 2b or 3 reperfusion & 0.05 & $7.30(0.60-88.62)$ \\
CoT treatment & 0.03 & $3.75(1.09-12.85)$ \\
MCA M2 vs. M1 segment & 0.15 & $3.04(0.66-14.05)$ \\
tICA vs. MCA M1 segment & 0.25 & $0.33(0.05-2.20)$ \\
Time from symptoms onset to recanalization & 0.11 & $0.99(0.98-1.00)$ \\
First-pass success & 0.15 & $0.41(0.12-1.37)$ \\
\hline
\end{tabular}

Forward stepwise logistic regression with dependent variable good clinical outcome (MrS score at 90 days: $0-1$ ). NIHSS National Institute of Health Stroke Scale, $T I C I$ thrombolysis in cerebral infarction grading scale, MCA middle cerebral artery, $t / C A$ terminal internal carotid artery, OR odd ratio, $m R S$ modified Rankin Scale, ASPECTS Alberta Stroke Program Early Computed Tomography Score, COT combined therapy

of tPA and is not in line with 2018 guidelines and their inclusion potentially introduce a bias of a delayed ET [3].

The possible reduction of EFIV supports the hypothesis of a direct effect of tPA treatment on potentially salvageable brain tissue. Moreover determination of EFIV may represent a valid outcome measure for future clinical trials, potentially having a higher inter-observer reliability compared to clinical assessment alone with the mRS $[12,13]$. The possible suggested mechanisms of action of adjunctive rtPA may be explained by a twofold effect: i) a favorable impact on endovascular procedure as suggested by the higher recanalization and higher first-pass success rates in CoT patients and, ii) an effectiveness of systemic tPA on preserving microvascular perfusion in downstream to the arterial occlusion, therefore improving benefit of large vessel recanalization 4 . Finally, another interesting result of our study is the lack of association between tPA and intracranial bleeding. This may have relevant implications for clinical practice,

Table 3 Details of procedural, clinical, and safety outcomes

\begin{tabular}{|c|c|c|c|}
\hline Variables & $\operatorname{CoT}(n=70)$ & Direct ET $(n=75)$ & PValue \\
\hline Time from symptoms onset to needle, Mean (SD), min & $156.1(37.6)$ & n.a & n.a \\
\hline Time from symptoms onset to groin puncture, Mean (SD), min & $194.1(59.9)$ & $204.8(60.4)$ & $0.32^{2}$ \\
\hline Time from symptoms onset to recanalization, Mean (SD), min & $245.9(75.8)$ & $245.1(58.6)$ & $0.95^{2}$ \\
\hline $\mathrm{TICl} 2 \mathrm{~b}$ or 3 reperfusion, $\mathrm{n}(\%)$ & $59(84.3)$ & $49(65.3)$ & $0.009^{1}$ \\
\hline Rates of first-pass success, \% & 62.7 & 38.6 & $<0.05^{1}$ \\
\hline $\mathrm{slCH}, \mathrm{n}(\%)$ & $7(10.0)$ & $8(10.6)$ & $0.87^{1}$ \\
\hline Cerebral infarct Volume, Mean (SD), ml & $16.4(25.3)$ & $62.3(81.7)$ & $0.003^{2}$ \\
\hline \multicolumn{4}{|l|}{ Outcome at 90 days } \\
\hline mRS score of $0-1, n(\%)$ & $34(48.5)$ & $14(18.6)$ & $<0.001^{1}$ \\
\hline mRS score of $0-2, n(\%)$ & $47(67.1)$ & $28(37.3)$ & $<0.001^{1}$ \\
\hline Mortality, n (\%) & $5(7.1)$ & $11(14.6)$ & $0.15^{1}$ \\
\hline
\end{tabular}

${ }^{1}$ Pearson's chi-squared test; ${ }^{2}$ Mann-Whitney test for unpaired groups; CoT combined therapy, ET endovascular therapy, SD standard deviation, ICH intracerebral hemorrhage, $m R S$ modified Rankin Scale, $T I C I$ thrombolysis in cerebral infarction grading scale 
highlighting that tPA treatment in eligible patients should not be withheld for the fear of intracranial hemorrhage. This finding is in line with available evidence [5-11, 18].

Some limitations should be considered in the interpretation of our findings such as relatively small sample size obtained from a single center retrospective analysis, nonrandomized comparison, potential risk of confounding by indication due to treatment allocation bias [subjects included in the ET group mostly consisted of patients with contraindications for IVT and therefore possibly weightened by worse prognosis, although the 2 groups are quite homogeneous for clinical and radiological features (see Table 1), lack of advanced neuroimaging-based patients' selection. We underline that, despite the treatment allocation bias, the two groups are homogeneous regarding the timing of the treatments. This can be explained by the fact that most patients in the ET group did not perform IVT not for exceeding time limit from symptoms onset but for other clinical reasons.

While taking them into full consideration, our data seems to confirm a favorable role of tPA in improving clinical and neuroradiological outcome of patients treated by endovascular mechanical thrombectomy for a large vessel occlusion stroke. The 4 ongoing prospective randomized controlled trials will better clarify this clinical issue.

\section{Conclusions}

The study confirms the safety and beneficial effect of CoT for anterior circulation AIS with LVO compared to direct ET. Coupling EFIV and mRS at 90 days assessment may represent a more reliable and possibly more powerful tool to be used in future clinical trials $[11,12]$.

\section{Abbreviations}

AIS: acute ischemic stroke; ASPECTS: Alberta stroke program early ct score; CIV: Cerebral infarct volume; COT: Combined therapy; CT: Computed tomography; DSA: Digital subtraction angiography; ECASS: European Cooperative Acute Stroke Study II; EFIV: early follow-up infarct volume; ET: Endovascular therapy; IVT: intravenous thrombolysis; LVO: large vessel occlusion; MCA: middle cerebral artery; mRS: modified Rankin Scale; NIHSS: National Institute Of Health Stroke Scale; RCTs: Randomized clinical trials; SICH: symptomatic intracerebral hemorrhage; tICA: terminal internal carotid artery; TICl: thrombolysis in cerebral infarction; TOAST: Trial of ORG 10172 in acute stroke treatment; tPA: recombinant tissue-plasminogen activator

\section{Acknowledgments}

We would like to thank all participants to the study and their families.

\section{Authors' contributions}

MG: study design, data acquisition, data interpretation, manuscript writing. NG: data acquisition, data analysis, data interpretation, manuscript writing. EP: data acquisition, data analysis, data interpretation, manuscript writing. AC: data acquisition, data interpretation, manuscript drafting. MF: data acquisition, data interpretation, manuscript drafting. DM: data acquisition, data interpretation, manuscript drafting. W: data acquisition, data interpretation, manuscript drafting. RS: data acquisition, data interpretation, manuscript drafting. ID: data acquisition, data interpretation, manuscript drafting. AM: data acquisition, data analysis, data interpretation, manuscript writing. LP: data acquisition, data interpretation, manuscript drafting. VDG: data acquisition, data interpretation, manuscript drafting. FC: data acquisition, data interpretation, manuscript drafting. AP: data acquisition, data interpretation, manuscript drafting. RG: data acquisition, data interpretation, manuscript drafting. AP: data acquisition, data interpretation, manuscript drafting. MG: data acquisition, data interpretation, manuscript drafting. All authors: i) approved the submitted version, ii) agreed both to be personally accountable for the author's own contributions and to ensure that questions related to the accuracy or integrity of any part of the work, even ones in which the author was not personally involved, are appropriately investigated, resolved, and the resolution documented in the literature.

\section{Funding}

This research received no specific grant from any funding agency in the public, commercial, or not-for-profit sectors.

\section{Availability of data and materials}

request of data (anonymized dataset) can be done directly to the Corresponding Author (Dr. Massimo Gamba, massimo.gamba@asst-spedalicivili.it).

\section{Ethics approval and consent to participate}

Ethical approval was not sought for this study because it was a retrospective study, as defined by local ethics committee (Spedali Civili Ethics Committee, Spedali Civili Hospital, Piazzale Spedali Civili, 1, 25123, Brescia, Italy). Written informed consent was obtained (by patients (if she/he was mentallycompetent) or by the next of kin in all the remaining cases (i.e. hemiparesis, aphasia). The consent was obtained for medical/interventional treatment for life-threatening condition (i.e. ischemic stroke) as well as for research purpose.

Consent for publication

Not applicable.

\section{Competing interests}

Dr. Andrea Morotti is Associated Editor of BMC Neurology; The others Authors declare that there is no competing interest.

\section{Author details}

${ }^{1}$ Stroke Unit, Neurologia Vascolare, ASST Spedali Civili di Brescia, Piazzale Spedali Civili 1, Brescia 25123 Brescia, Italy. ${ }^{2}$ Servizio di Neuroradiologia, Università degli Studi di Brescia, Brescia, Italy. ${ }^{3}$ Dipartimento di Scienze Mediche e Chirurgiche, Clinica Neurologica, Università degli Studi di Brescia, Brescia, Italy. ${ }^{4}$ Stroke Unit, IRCCS Fondazione Istituto Neurologico Nazionale "C. Mondino", Pavia, Italy.

Received: 4 January 2019 Accepted: 23 May 2019

Published online: 29 May 2019

\section{References}

1. Nogueira RG, Jadhav AP, Haussen DC, Bonafe A, Budzik RF, Bhuva P, Yavagal DR, Ribo M, Cognard C, Hanel RA, Sila CA, Hassan AE, Millan M, Levy El, Mitchell P, Chen M, English JD, Shah QA, Silver FL, Pereira VM, Mehta BP, Baxter BW, Abraham MG, Cardona P, Veznedaroglu E, Hellinger FR, Feng L, Kirmani JF, Lopes DK, Jankowitz BT, Frankel MR, Costalat V, Vora NA, Yoo AJ, Malik AM, Furlan AJ, Rubiera M, Aghaebrahim A, Olivot JM, Tekle WG, Shields R, Graves T, Lewis RJ, Smith WS, Liebeskind DS, Saver JL, Jovin TG. Thrombectomy 6 to 24 hours after stroke with a mismatch between deficit and infarct. N Engl J Med. 2018;378:11-21.

2. Albers GW, Marks MP, Kemp S, Christensen S, Tsai JP, Ortega-Gutierrez S, McTaggart RA, Torbey MT, Kim-Tenser M, Leslie-Mazwi T, Sarraj A, Kasner SE. Thrombectomy for Stroke at 6 to 16 Hours with Selection by Perfusion Imaging. 2018;378:708-18.

3. Powers WJ, Rabinstein AA, Ackerson T, Adeoye OM, Bambakidis NC, Becker K, Biller J, Brown M, Demaerschalk BM, Hoh B, Jauch EC, Kidwell CS, LeslieMazwi TM, Ovbiagele B, Scott PA, Sheth KN, Southerland AM, Summers DV, Tirschwell DL. 2018 guidelines for the early Management of Patients with Acute Ischemic Stroke: a guideline for healthcare professionals from the American Heart Association/American Stroke Association. Stroke. 2018;49: e46-e110

4. Chandra RV, Leslie-Mazwi TM, Mehta BP, Derdeyn CP, Demchuk AM, Menon $B K$. Does the use of IV tPA in the current era of rapid and predictable recanalization by mechanical embolectomy represent good value? vol. 8; 2016. p. 443-6. 
5. Leker RR, Pikis S, Gomori JM, Cohen JE. Is bridging necessary? A pilot study of bridging versus primary Stentriever-based endovascular reperfusion in large anterior circulation strokes. J Stroke Cerebrovasc Dis. 2015;24:1163-7.

6. Tsivgoulis G, Katsanos AH, Mavridis D, Alexandrov AW, Magoufis G, Arthur A, Caso V, Schellinger PD, Alexandrov AV. Endovascular thrombectomy with or without systemic thrombolysis? Ther Adv Neurol Disord. 2017;10:151-60.

7. Coutinho JM, Liebeskind DS, Slater LA, Nogueira RG, Clark W, Davalos A, Bonafe A, Jahan R, Fischer U, Gralla J, Saver JL, Pereira VM. Combined intravenous thrombolysis and Thrombectomy vs Thrombectomy alone for acute ischemic stroke: a pooled analysis of the SWIFT and STAR studies. JAMA Neurol. 2017;74:268-74.

8. Merlino G, Sponza M, Petralia B, Vit A, Gavrilovic V, Pellegrin A, Rana M, Cancelli I, Naliato S, Lorenzut S, Marinig R, Calzolari F, Eleopra R. Short and long-term outcomes after combined intravenous thrombolysis and mechanical thrombectomy versus direct mechanical thrombectomy: a prospective single-center study. J Thromb Thrombolysis. 2017;44:203-9.

9. Mistry EA, Mistry AM, Nakawah MO, Chitale RV, James RF, Volpi JJ, Fusco MR. Mechanical Thrombectomy outcomes with and without intravenous thrombolysis in stroke patients: a meta-analysis. Stroke. 2017:48:2450-6.

10. Abilleira S, Ribera A, Cardona P, Rubiera M, Lopez-Cancio E, Amaro S, Rodriguez-Campello A, Camps-Renom P, Canovas D, de Miquel MA, Tomasello A, Remollo S, Lopez-Rueda A, Vivas E, Perendreu J, Gallofre M. Outcomes after direct Thrombectomy or combined intravenous and endovascular treatment are not different. Stroke. 2017:48:375-8.

11. Wang H, Zi W, Hao Y, Yang D, Shi Z, Lin M, Wang S, Liu W, Wang Z, Liu X, Guo F, Liu Y, Xu G, Xiong Y (2017) Direct endovascular treatment: an alternative for bridging therapy in anterior circulation large-vessel occlusion stroke. 24, 935-943.

12. Yushkevich PA, Piven J, Hazlett HC, Smith RG, Ho S, Gee JC, Gerig G. Userguided $3 \mathrm{D}$ active contour segmentation of anatomical structures: significantly improved efficiency and reliability. Neuroimage. 2006;31:1116-28.

13. Ernst M, Boers AMM, Aigner A, Berkhemer OA, Yoo AJ, Roos YB, Dippel DWJ, van der Lugt A, van Oostenbrugge RJ, van Zwam WH, Fiehler J, Marquering HA, Majoie C. Association of Computed Tomography Ischemic Lesion Location with Functional Outcome in acute large vessel occlusion ischemic stroke. Stroke. 2017:48:2426-33.

14. Wahlgren N, Ahmed N, Davalos A, Ford GA, Grond M, Hacke W, Hennerici MG, Kaste M, Kuelkens S, Larrue V, Lees KR, Roine RO, Soinne L, Toni D, Vanhooren G. Thrombolysis with alteplase for acute ischaemic stroke in the Safe implementation of thrombolysis in stroke-monitoring study (SITSMOST): an observational study. Lancet. 2007;369:275-82.

15. Barber PA, Demchuk AM, Zhang J, Buchan AM. Validity and reliability of a quantitative computed tomography score in predicting outcome of hyperacute stroke before thrombolytic therapy. ASPECTS Study Group Alberta Stroke Programme Early CT Score Lancet. 2000;355:1670-4.

16. Higashida RT, Furlan AJ, Roberts H, Tomsick T, Connors B, Barr J, Dillon W, Warach S, Broderick J, Tilley B, Sacks D. Trial design and reporting standards for intra-arterial cerebral thrombolysis for acute ischemic stroke. Stroke. 2003;34:e109-37.

17. Hacke W, Kaste M, Fieschi C, von Kummer R, Davalos A, Meier D, Larrue V, Bluhmki E, Davis S, Donnan G, Schneider D, Diez-Tejedor E, Trouillas P. Randomised double-blind placebo-controlled trial of thrombolytic therapy with intravenous alteplase in acute ischaemic stroke (ECASS II). Second EuropeanAustralasian Acute Stroke Study Investigators Lancet. 1998;352:1245-51.

18. Goyal M, Demchuk AM, Menon BK, Eesa M, Rempel JL, Thornton J, Roy D, Jovin TG, Willinsky RA, Sapkota BL, Dowlatshahi D, Frei DF, Kamal NR, Montanera WJ, Poppe AY, Ryckborst K, Silver FL, Shuaib A, Tampieri D, Williams D, Bang OY, Baxter BW, Burns PA, Choe H, Heo JH, Holmstedt CA, Jankowitz B, Kelly M, Linares G, Mandzia JL, Shankar J, Sohn SI, Swartz RH, Barber PA, Coutts SB, Smith EE, Morrish WF, Weill A, Subramaniam S, Mitha AP, Wong JH, Lowerison MW, Sajobi TT, Hill MD. Randomized assessment of rapid endovascular treatment of ischemic stroke. N Engl J Med. 2015;372:1019-30.

\section{Publisher's Note}

Springer Nature remains neutral with regard to jurisdictional claims in published maps and institutional affiliations.

\section{Ready to submit your research? Choose BMC and benefit from:}

- fast, convenient online submission

- thorough peer review by experienced researchers in your field

- rapid publication on acceptance

- support for research data, including large and complex data types

- gold Open Access which fosters wider collaboration and increased citations

- maximum visibility for your research: over $100 \mathrm{M}$ website views per year

At BMC, research is always in progress.

Learn more biomedcentral.com/submissions 